\title{
Association between GABA3 Gene Polymorphisms and Attention Deficit Hyperactivity Disorder in Korean Children
}

\author{
Ho Jang Kwon ${ }^{1,2}$, Wook Kim³ , and Myung Ho Lim ${ }^{1,4} \bowtie$ \\ ${ }^{1}$ Environmental Health Center, Dankook Medical Hospital, Cheonan, Republic of Korea \\ ${ }^{2}$ Department of Preventive Medicine, College of Medicine, Dankook University, Cheonan, Republic of Korea \\ ${ }^{3}$ Department of Biological Sciences, College of Natural Science, Dankook University, Cheonan, Republic of Korea \\ ${ }^{4}$ Department of Psychology, College of Public Welfare, Dankook University, Cheonan, Republic of Korea
}

Objective Attention deficit hyperactivity disorder (ADHD) is common disorder of the school-age population. ADHD is familial and genetic studies estimate heritability at $80-90 \%$. The aim of the present study was to investigate the association between the genetic type and alleles for gamma-aminobutyric acid receptor subunit beta-3 (GABA3) gene in Korean children with ADHD.

Methods The sample consisted of 180 ADHD children and 159 control children. We diagnosed ADHD according to DSM-IV. ADHD symptoms were evaluated with Conners' Parent Rating Scales and Dupaul Parent ADHD Rating Scales. Blood samples were taken from the 339 subjects, DNA was extracted from blood lymphocytes, and PCR was performed for GABA3 rs2081648, rs1426217 and rs981778 Polymorphism. Alleles and genotype frequencies were compared using the chi-square test. We compared the allele and genotype frequencies of GABA3 gene polymorphism in the ADHD and control groups.

Results This study showed that there was a significant correlation among the frequencies of the rs $2081648(\mathrm{OR}=0.71,95 \% \mathrm{CI}=0.51-0.98$, $\mathrm{p}=0.040$ ) of alleles of MAO, but the final conclusions are not definite. Follow up studies with larger patient or pure subgroups are expected. Conclusion These results suggested that GABA3 might be related to ADHD symptoms.

Psychiatry Investig 2017;14(5):693-697

Key Words ADHD, Polymorphism, GABA, Korean children.

\section{INTRODUCTION}

Attention deficit hyperactivity disorder (ADHD) is a common childhood neuropsychiatric disorder characterized by behavioral problems such as attention deficit, hyperactivity and impulsivity. ${ }^{1}$ It has a prevalence of $2-7.6 \%$ among children of school age in Korea. ${ }^{2,3}$ Family studies reported that ADHD showed a heredity as high as $80-90 \%,{ }^{4}$ and molecular genetic studies are actively carried out accordingly. Recent genetic studies on ADHD have usually been conducted on the dopamine receptors and related neurotransmitters.

GABRB3 gene encodes a member of the ligand-gated ion channel family. The encoded protein is one of at least 13 dis-

Received: June 20, 2016 Revised: August 25, 2016

Accepted: August 31, 2016 Available online: May 17, 2017

$\triangle$ Correspondence: Myung Ho Lim, MD, PhD

Department of Psychology, College of Public Welfare, Dankook University, 119 Dandae-ro, Dongnam-gu, Cheonan 31616, Republic of Korea

Tel: +82-41-550-3263, Fax: +82-41-559-7852, E-mail: paperose@dku.edu

(a) This is an Open Access article distributed under the terms of the Creative Commons Attribution Non-Commercial License (http://creativecommons.org/licenses/bync/4.0) which permits unrestricted non-commercial use, distribution, and reproduction in any medium, provided the original work is properly cited. tinct subunits of a multisubunit chloride channel that serves as the receptor for gamma-aminobutyric acid, the major inhibitory transmitter of the nervous system. This gene is located on the long arm of chromosome 15 in a cluster with two genes encoding related subunits of the family (Figure 1).

The GABRB3 gene deficient mouse has been proposed as a model of autism spectrum disorder. ${ }^{5}$ The genes encoding for $\mathrm{GABA}_{\mathrm{A}}$ receptor subunits have been identified on chromosome 15q11-q13 which contains $\mathrm{GABA}_{\mathrm{A}}$ receptor $\beta 3$ (GABARB3), $\alpha 5$ (GABRA5), and $\gamma 3$ (GABRG3) subunit genes which appear to be a cluster. Recently, McCauley et al. ${ }^{6}$ reported the likely existence of one or more autism risk SNP alleles in the $\mathrm{GABA}_{\mathrm{A}}$ receptor subunit cluster, especially GABRB3.

Studies of ADHD on GABAergic dysfunction have very few. The GABAergic system plays a crucial role in early neural development. ${ }^{7}$ A study found that the $\gamma$-aminobutyric acid (GABA) level in the blood increased and the ratio of excitatory/inhibitory mediatory amino acids decreased significantly in children with minimal cerebral dysfunction; ${ }^{8}$ GABA concentration is reduced in children with ADHD compared with typically developing control subjects. ${ }^{9}$ Moreover, the GAB- 


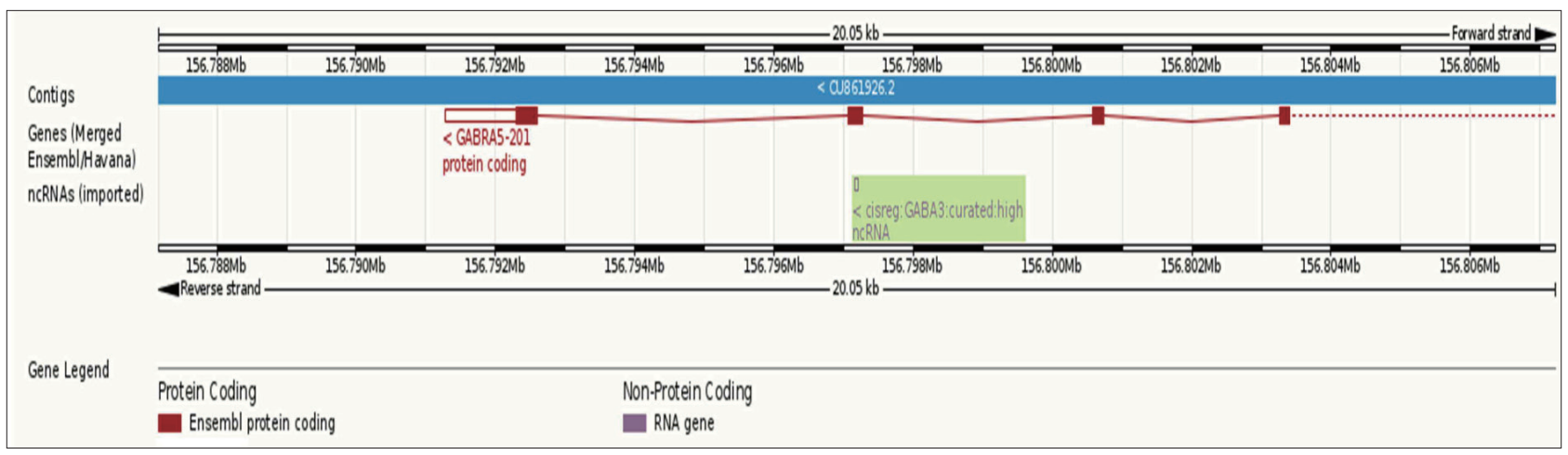

Figure 1. The drawing of the GABA3 receptor subunit gene.

Table 1. Epidemiological characteristics between the ADHD group and the control group

\begin{tabular}{lccc}
\hline \multicolumn{1}{c}{ Rating scale } & $\begin{array}{c}\text { ADHD group }(\mathrm{N}=180) \\
\text { Mean } \pm \text { SD }\end{array}$ & $\begin{array}{c}\text { Control group }(\mathrm{N}=159) \\
\text { Mean } \pm \text { SD }\end{array}$ & F or $\chi^{2}$ \\
\hline Age $^{*}$ & $8.67 \pm 0.84$ & $8.59 \pm 0.79$ & 0.06 \\
Sex $(\mathrm{N}, \%)^{\dagger}$ & & & 3.79 \\
Female & $48(26.7)$ & $59(37.1)$ & 0.013 \\
Male & $132(73.3)$ & $100(62.9)$ & \\
\hline
\end{tabular}

These data represent mean \pm SD, by independent $t$ test*, or $\mathrm{N}(\%)$, by chi-square test ${ }^{\dagger}$, significant $\mathrm{p}$ value $<0.05$. ADHD: attention-deficit/hyperactivity disorder

Aergic agent extended-release valproate (EVA) could decrease ADHD symptoms. ${ }^{10,11}$ Whether GABAergic dysfunction has direct or indirect importance in ADHD is unclear, and an association study between the GABAergic genes and ADHD may be able to clarify its role in the susceptibility to ADHD. To date, the correlation of polymorphisms in GABAergic genes to ADHD has not been reported. GABRB3 encodes the $\mathrm{B} 3$ subunit of the $\mathrm{GABA}_{\mathrm{A}}$ receptor. $\mathrm{GABA}_{\mathrm{A}}$ receptor is an ionotropic, ligand-gated receptor, which is part of the inhibitory synapses in the adult brain, and selectively conducts $\mathrm{Cl}$ ions. During development, GABRB3 is an important molecule for neuronal growth and differentiation, and mediates excitatory signaling. ${ }^{12,13}$

Wang et al. ${ }^{14}$ conducted a study with 54 subjects having ADHD and 67 healthy control members residing in China. The result showed that GABA rs1805057 SNP only did not have a significant correlation with ADHD. Kim et al. ${ }^{15}$ conducted a study with 104 autism patients and trio family members by performing rs2081648, rs1426217, rs890317, and rs981778 SNP. The result showed that an allele at rs2081648 showed preferential transmission $(\mathrm{p}=0.027)$. But this study was the association of GABA and Autism in Korea. No study has been conducted in Korea to show the correlation between GABA3 gene polymorphism and ADHD.

The aim of the present study was to investigate the association between the genetic type and alleles for GABA3 gene in Korean children with ADHD.

\section{METHODS}

\section{Subjects}

A questionnaire was conducted with about 16,000 elementary school students in a city whose population is about 500,000 from September 2008 and August 2010. A interview was performed randomly with the children whose Korean version of the DuPaul Attention Deficit Hyperactivity Disorder Rating Scale (K-ARS) ${ }^{16}$ score was 19 or higher, and 180 ADHD children who consented to the genetic study were selected. For the control group, 159 children in the same area were selected by matching the sex and age of the subjects in the patient group. For both of the patient and control groups, a clinical evaluation and the DSM-IV diagnosis ${ }^{1}$ were performed by a child psychiatrist. The number of ADHD children was 180, including 132 boys ( $73.3 \%)$ and 48 girls (26.7\%), and the mean age was $8.67 \pm 0.84$. The number of the children in the control group was 159 , including 100 boys (62.9\%) and 59 girls (37.1\%), and the mean age was $8.59 \pm 0.79$. There was no significant difference in the sex and age between the two groups (Table 1). Subjects were excluded from the study if there was any evidence of conduct disorder, mood disorder, anxiety disorder, Tourette's disorder, pervasive developmental disorder, mental retardation (IQ <70) and neurological disorders including epilepsy. None of the children who participated in the study has ever undergone drug treatment before the evaluation. Informed consent was obtained prior to study entry. The study was also approved by the Hospital Ethics Committee. None of the chil- 
dren was taking psychostimulants at the time of the study.

On the day of visiting the hospital, the child psychiatrist performed a clinical interview as well as Kovac's Children's Depression Inventory (CDI), ${ }^{17}$ State Anxiety Inventory for children (SAIC), ${ }^{18}$ Trait Anxiety Inventory for children (TAIC) and DuPaul Attention Deficit Hyperactivity Disorder Rating Sales (K-ARS), ${ }^{19}$ computerized ADHD Diagnostic System (ADS) as well as completing a questionnaire survey regarding the pregnancy, infancy, developmental history and anamnesis of the children with their parents. Subjects were included from our sample if they had a score over two standard deviations from the norm on the tests for ADS (T-score $>70$ ). ADHD had a lot of comorbid disorders, such as depressive disorder and anxiety disorder. So we excluded children with the high score of depressive symptoms and anxiety symptoms. Subjects with high anxiety scores (a Spielberger trait/state anxiety scale score $>47 / 49$ ) on the Korean version of Spielberger trait-state anxiety scale for children were excluded, and subjects with high depression scores (Kovacs depression inventory score $>29$ ) on Kovacs depression inventory for children were also excluded. In addition, a professional clinical psychologist performed a comprehensive psychological test, including an intelligence test, on each subject.

\section{DNA extraction and genotyping}

DNA was extracted from leukocytes using a commercial DNA extraction kit, the Wizard Genomic DNA purification kit (Promega, Madison, WI, USA). The GABA3 SNP was genotyped by polymerase chain reaction (PCR) according to the protocol described by studies ${ }^{15}$ GABA3 rs2081648, rs 1426217 and rs981778 were genotyped by Illumina, Inc. (San Diego, CA, USA) through the use of their Integrated Bead Array System (Table 2). We supplied Ilumina with barcoded DNA microtiter plates containing the DNA quantified with Pico Green to be at $100 \mathrm{ng} / \mathrm{mL}$ and Ilumina delivered genotypes with quality scores calculated by proprietary Ilumina algorithms. Genotyping methods for the Korean samples were previously reported. ${ }^{15}$

\section{Statistical analysis}

We performed independent $t$ tests for age, chi-square tests for sex, and chi-squre tests to compare the results of the con- trol group and the ADHD group through the frequency of the genotypes and alleles. SPSS PC software (version 15.0; SPSS Inc., Chicago, IL, USA) was used for the statistical analysis and the significance level was set to the $\mathrm{p}$ value being less than 0.05 . Our study was conducted with 339 subjects and the power was $97.41 \%$. This indicates that the association of the GABA3 gene polymorphism and ADHD can be sufficiently accounted for by the results in this study. However, we performed the power program analysis for the chi-square test with 339 subjects and the result showed that the effect size was 0.43 (moderate level).

\section{RESULTS}

\section{Demographic characteristics of the subjects}

The subjects were a total of 339 children. The children in both of the ADHD group and the control group had never taken any psychostimulants in advance. There was no difference in the age $(\mathrm{F}=0.06, \mathrm{p}=0.813)$ and $\operatorname{sex}(\mathrm{F}=3.79, \mathrm{p}=0.052)$ between the control group and the ADHD children group (Table 2).

\section{Comparison of the frequency of the genotypes and alleles with genetic polymorphism of $G A B A 3$ between the control group and the ADHD group}

The GABA3-rs2081648 genotypes of the 159 subjects in the control group and the 180 subjects in the ADHD group were G/G (56.18\% vs. $41.77 \%)$, G/A (35.39\% vs. $49.37 \%)$ and A/A ( $8.43 \%$ vs. $8.86 \%)$, and there was a significant difference in the frequency between the two groups $\left(\chi^{2}=-2.63, \mathrm{df}=2, \mathrm{p}=0.009\right)$ (Table 3).

The GABA3-rs2081648 allele of the 159 subjects in the control group and the 180 subjects in the ADHD group were $G$ alleles (73.88\% vs. $66.46 \%$ ) and A alleles (26.12\% vs. $33.54 \%$ ), and there was a significant difference in the frequency of allele between the two groups $\left(\chi^{2}=-2.06, \mathrm{df}=1, \mathrm{p}=0.040\right)$ (Table 3 ).

\section{Odds ratio of the genotypes and alleles with genetic polymorphism of $G A B A 3$ between the control group and the ADHD group}

The odds ratio of the GABA3-rs2081648 genotypes was significant at 0.56 (confidence interval: $0.36-0.86, \mathrm{p}=0.009$ ) and the odds ratio of the $G A B A 3-$ rs2081648 allele of was significant at 0.71 (confidence interval: $0.51-0.98, \mathrm{p}=0.040$ ) (Table 3).

Table 2. SNPs considered in this study

\begin{tabular}{cccccc}
\hline SNP ID & Chromosome & Location & Position (coordinate) & Distance & Alleles \\
\hline GABA3 & & & & & \\
rs2081648 & 15 & Intron & 24349291 & -4918 & G/A \\
rs1426217 & 15 & Intron & 24372217 & -4341 & T/C \\
rs981778 & 15 & 3UTR & 24508332 & -60309 & G/A \\
\hline
\end{tabular}

GABA3: $\gamma$-aminobutyric acid gene, NCBI gene ID (Accession) is 2562 (NM00081 and NM02191). SNP: single nucleotide polymorphism 
Table 3. Multivariate model for genotype distributions and allele frequencies of the ADHD group and the control group

\begin{tabular}{|c|c|c|c|c|c|c|c|c|}
\hline \multirow{2}{*}{ Characteristics } & \multicolumn{2}{|c|}{ Control } & \multicolumn{2}{|c|}{ ADHD } & \multirow{2}{*}{ OR } & \multirow{2}{*}{$95 \%$ CI } & \multirow{2}{*}{$\chi^{2}$} & \multirow{2}{*}{$\mathrm{p}$} \\
\hline & $\mathrm{N}$ & $\%$ & $\mathrm{~N}$ & $\%$ & & & & \\
\hline \multicolumn{9}{|l|}{ GABA-rs2081648 (G/A) } \\
\hline Genotype & & & & & 0.56 & $0.36-0.86$ & -2.63 & 0.009 \\
\hline GG & 100 & 56.18 & 66 & 41.77 & & & & \\
\hline GA & 63 & 35.39 & 78 & 49.37 & & & & \\
\hline AA & 15 & 8.43 & 14 & 8.86 & & & & \\
\hline Allele & & & & & 0.71 & $0.51-0.98$ & -2.06 & 0.040 \\
\hline A & 263 & 73.88 & 210 & 66.46 & & & & \\
\hline $\mathrm{C}$ & 93 & 26.12 & 106 & 33.54 & & & & \\
\hline \multicolumn{9}{|l|}{ GABA-rs1426217 (T/C) } \\
\hline Genotype & & & & & 0.92 & $0.55-1.54$ & -0.32 & 0.751 \\
\hline $\mathrm{TT}$ & 140 & 78.65 & 122 & 77.21 & & & & \\
\hline TC & 36 & 20.22 & 35 & 22.15 & & & & \\
\hline $\mathrm{CC}$ & 2 & 1.12 & 1 & 0.63 & & & & \\
\hline Allele & & & & & 0.97 & $0.61-1.55$ & -0.114 & 0.909 \\
\hline $\mathrm{T}$ & 316 & 88.76 & 279 & 88.29 & & & & \\
\hline $\mathrm{C}$ & 40 & 11.24 & 37 & 11.71 & & & & \\
\hline \multicolumn{9}{|l|}{ GABA-rs981778 (G/A) } \\
\hline Genotype & & & & & 1.03 & $0.66-1.62$ & 0.13 & 0.900 \\
\hline GG & 116 & 65.17 & 104 & 65.82 & & & & \\
\hline AG & 51 & 28.65 & 49 & 35.01 & & & & \\
\hline AA & 11 & 6.18 & 5 & 3.16 & & & & \\
\hline Allele & & & & & 1.13 & $0.77-1.65$ & 0.64 & 0.522 \\
\hline G & 283 & 79.49 & 257 & 81.33 & & & & \\
\hline $\mathrm{A}$ & 73 & 20.51 & 59 & 18.67 & & & & \\
\hline
\end{tabular}

These data represent $\mathrm{N}(\%)$ by chi-square test, significant $\mathrm{p}$ value $<0.05$. ADHD: attention deficit hyperactivity disorder, GABA: $\gamma$-aminobutyric acid

\section{DISCUSSION}

This study is a case-controlled study in which the frequency of the genotypes and alleles of $G A B A 3$ were compared between the ADHD children and the control group in Korea. The correlation between the genotypes and alleles of one candidate GABA3 SNPs was investigated. This study showed that there was a significant correlation between the frequencies of the GABA3-rs2081648, this result is first report for the association between GABA3 and ADHD children. This study showed that there was a significant correlation between the frequencies of the GABA3-rs2081648 and ADHD. To our knowledge, this result is first report on the association between the GABA3 polymorphism and ADHD. In the study of Korean children, reported which is the only previous study about the association between autism and $G A B A 3$, Kim et al. ${ }^{15}$ reported the association between rs 2081648 genetic polymorphism of the $G A B A 3$ gene and Autism was reported first in Korea. But in this study, the correlation between ADHD and GABA3-rs2081648 genetic polymorphism was found in this study firstly.
Combining the results about the correlation between the GABA3-rs2081648 and ADHD, it can be understood that the failure of $G A B A 3$ regulation may cause the changes in catecholamine and may be correlated with the vulnerability of various psychiatric diseases including ADHD and movement disorder. These receptors can affect the catecholamine mediating action, which is related with the symptoms found in the children with ADHD.

This study also suggests that the failure to regulate the $G A B A 3$ expression causes changes in the catecholamine expression and the structural development of the brain regions related with nerve activity, attention and impulsivity. In this study, we assumed that the variation of the $G A B A 3$ gene affect these SNPs that are the cause of ADHD. Hence, the correlation between the GABA3 gene and ADHD should be carefully handled and the result of our study should be verified in the future study with a large number of independent samples.

The limitations of this study are as follows: first, the number of subject children was small. The subjects of this study were $180 \mathrm{ADHD}$ children and 159 children in the control group. 
Second, the results of this study may not be generalized for the cases of other racial or ethnic groups since the frequency of alleles can vary due to local or racial differences. The distribution of the allele frequency in the ADHD patient children and parents group in this study was also different from that of other countries. Third, only a few SNPs were investigated in this study among the many genes related with the various ADHD phenotypes. Although it is clear that not just one genetic factor causes the increased ADHD vulnerability, we did not consider the interaction with other risk factors.

Despite the methodological limitations described before, this study has several advantages. First, the patient group and the control group had no difference in the frequency of sex and age. The prevalence of ADHD is higher among males and in adolescence; thus, the sex and age characteristics can have a great effect. Considering this, our study was evaluated by matching the age and sex of the patient group and the control group with each other. Second, this study used population-based samples. Previous studies in Korea were hardly considered to represent the general population because the subjects were usually ADHD children who visited hospitals for their clinical symptoms. In this study, the subjects in the risk group were selected by the questionnaire survey from the whole population in a region and the patient and control samples were obtained by random contact. Thus, the subjects in this study may be more appropriate to the characteristics of general population than those of the study performed with the patients who visited hospitals. Third, this study might have compared relatively homogenous groups that had the characteristics of Koreans, different from the studies conducted in other countries with subjects from various ethnic groups and nations. Fourth, both the patient group and control group in this study underwent clinical evaluation and DSM-IV diagnosis by children psychiatrists, applying the inclusion and exclusion criteria strictly, and thus the patient group was composed of pure $\mathrm{ADHD}$ diagnosed subjects.

We expect that different allele distribution results may be produced from future studies on the quantitative correlation of the ADHD performance in the pure ADHD group from which co-existing diseases are excluded, the patients group composed of only boys or girls, the subtype groups such as hyperactivity dominant group and attention deficiency dominant group, and the drug response group.

\section{Acknowledgments}

The present research was conducted by the research fund of Dankook university in 2016.

\section{REFERENCES}

1. American Psychiatric Association Committee on Nomenclature and
Statistics. Diagnostic and Statistical Manual of Mental Disorders (DSM-IV), Fourth Edition. Washington, DC: American Psychiatric Association Press; 1994.

2. Cho SC, Shin YO. Prevalence of disruptive behavior disorders. Korean J Child Adolesc Psychiatry 1994;5:141-149.

3. Kim JY, Ahn DH, Shin YJ. An epidemiological study of attention deficit hyperactivity disorder and learning disabilities in a rural area. J Korean Neuropsychiatr Assoc 1999; 38:788-793.

4. Faraone SV, Doyle AE. The nature and heritability of attention-deficit/ hyperactivity disorder. Child Adolesc Psychiatr Clin N Am 2001;10:299316.

5. DeLorey TM, Sahbaie P, Hashemi E, Homanics GE, Clark JD. “Gabrb3 gene deficient mice exhibit impaired social and exploratory behaviors, deficits in non-selective attention and hypoplasia of cerebellar vermal lobules: a potential model of autism spectrum disorder". Behav Brain Res 2008;187:207-220.

6. McCauley JL, Olson LM, Delahanty R, Amin T, Nurmi EL, Organ EL, et al. A linkage disequilibrium map of the 1-Mb 15q12 GABA(A) receptor subunit cluster and association to autism. Am J Med Genet B Neuropsychiatr Genet 2004;131B:51-59.

7. Samaco RC, Hogart A, LaSalle JM. Epigenetic overlap in autism-spectrum neurodevelopmental disorders: MECP2 deficiency causes reduced expression of UBE3A and GABRB3. Hum Mol Genet 2005;14: 483-492.

8. Kolesnichenko LS, Kulinskii VI, Gorina AS. Amino acids and their metabolites in blood and urine of children with minimal cerebral dysfunction. Vopr Med Khim 1999;45:58-64.

9. Edden RA, Crocetti D, Zhu H, Gilbert DL, Mostofsky SH. Reduced GABA concentration in attention-deficit/hyperactivity disorder. Arch Gen Psychiatry 2012;69:750-753.

10. Miyazaki M, Ito H, Saijo T, Mori K, Kagami S, Kuroda Y. Favorable response of ADHD with giant SEP to extended-release valproate. Brain Dev 2006;28:470-472.

11. Powell SG, Thomsen PH, Frydenberg M, Rasmussen H. Long-term treatment of ADHD with stimulants: a large observational study of reallife patients. J Atten Disord 2011;15:439-451.

12. Ben-Ari Y, Khazipov R, Leinekugel X, Caillard O, Gaiarsa JL. GABAA, NMDA and AMPA receptors: a developmentally regulated 'ménage à trois'. Trends Neurosci 1997;20:523-529.

13. Herlenius E, Lagercrantz H. Development of neurotransmitter systems during critical periods. Exp Neurol 2004;190(Suppl 1):S8-S21.

14. Wang GX, Ma YH, Wang SF, Ren GF, Guo H. Association of dopaminergic/GABAergic genes with attention deficit hyperactivity disorder in children. Mol Med Rep 2012;6:1093-1098.

15. Kim SA, Kim JH, Park M, Cho IH, Yoo HJ. Association of GABRB3 polymorphisms with autism spectrum disorders in Korean trios. Neuropsychobiology 2006;54:160-165.

16. Kim YS, So YK, Noh JS, Koh YJ. The reliability and validity of Korean parent and teacher ADHD Rating Scale. J Korean Neuropsychiatr Assoc 2002;41:283-289.

17. Kovacs M. The Children's Depression Inventory: A Self-Rated Depression Scale for School-Aged Youngsters. Pittsburgh: University of Pittsburgh; 1983.

18. Cho SC, Choi JS. Development of Korean form of the state-trait anxiety inventory for children. J Seoul Psychiatry 1989;14:150-157.

19. Shin MS, Cho SC, Chun SY, Hong KM. A study of the development and standardization of ADHD diagnostic system. Korean J Child Adolesc Psychiatry 2000;11:91-99. 